\title{
INTELLIGENT LPG GAS LEAK DETECTION AND AUTOMATIC GAS BOOKING ALERT SYSTEM USING PIC MICROCONTROLLER
}

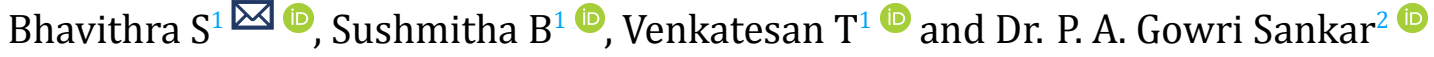 \\ ${ }^{1}$ Student, Electrical and Electronics Engineering,, Knowledge Institute of Technology, Salem, Tamil Nadu, India \\ Assistant Professor, Department of Electrical and Electronics Engineering, Knowledge Institute of Technology, Salem, \\ Tamil Nadu, India
}

Received 9 April 2021

Accepted 22 April 2021

Published 11 May 2021

Corresponding Author

Bhavithra S, bhavithra1999@gmai l.com

DOI $10.29121 /$

IJOEST.v5.i3.2021.184

Funding: This research received no specific grant from any funding agency in the public, commercial, or not-for-profit sectors.

Copyright: (C) 2021 The Author(s). This is an open access article distributed under the terms of the Creative Commons Attribution License, which permits unrestricted use, distribution, and reproduction in any medium, provided the original author and source are credited.

\section{ABSTRACT}

LPG gas is primarily used for cooking in our country. This paper focuses on continuous monitoring, booking and leakage detection in household LPG cylinder. In this system we have used PIC 16F877A microcontroller, GSM SIM 800c module and ESP8266 for monitoring and detection purpose. If gas level goes low, it helps us to make automatic booking of new gas cylinder using GSM module. Gas level is monitored with the help of the load cell and the current level of the cylinder can be viewed at any time in our mobile phone with the help of mobile application. The gas leakage is sensed with the help of MQ-6 gas sensor. When any leakage is detected, it turns on the buzzer and also alerts the consumer through a message. An automatic closure of cylinder valve is done using a solenoid valve and exhaust fans are switched on. By detecting gas leakage, we can avoid accidents which causes damage to life and property.

Keywords: PIC Microcontroller, Load Cell, Gas Sensor, Solenoid Valve, Leakage Detection, Booking

\section{INTRODUCTION}

In many countries, LPG is the majorly used fuel for commercial purpose. LPG is the most preferred fuel for cooking and it is more convenient. LPG cylinder is one of the essential in our daily life. The problem arises during the leakage and the user does not know the amount of LPG left in the cylinder. Our system is for the purpose to help the consumers to customize their safety standards, and most influential function is to prevent accidents and protect the life and safety precaution from several phenomenon. Because of this, the user cannot prebook the cylinder. Due to rising demand the user is has to prebook the cylinder. The cylinder is kept above the load cell, it measures the pressure of the cylinder. A MQ-6 gas sensor is used to determine the sensation of leakage in LPG gas. This signal is sent to the microcontroller, With 
the help of GSM module alert SMS is sent to the user. This activates the electric signal which is used to cut off the solenoid valve.

The objective of the system is,

- Gas cylinder is Booking automatically.

- LPG leakage is detected by the sensor and the information is sent to the user via SMS.

- Auto cut off gas valve, turn ON buzzer and exhaust fan is done at the time of leakage.

- Viewing the level of cylinder and leakage level through mobile application

\section{EXISTING SYSTEM}

The existing system uses Load cell, Arduino UNO, Bluetooth module and gas sensor for measuring the level of gasoline content and predict if any gas leakage occurs to notify the user. This system consists of load sensor networked with Arduino UNO and the Bluetooth module for connectivity. The weight measuring load sensor is linked to a mechanically designed adjustable trolley which holds the cylinder. The load sensor is fixed towards the bottom of this plate measures the weight of the cylinder systematically address the data to HX711 amplifier. The amplifier converts the Analog signal to digital signals and sends it to the Arduino UNO. The whole working on the system is performed by enforcing the code inbuild in the Arduino, it gets the input readings of load sensor and send the obtained output results of the present state of gasoline level, and it also gives alert of gas booking once the gas is below the threshold value. The expected results are notified to the user on their mobile phone via Bluetooth module. The output and results are displayed and notified to the user through the mobile application. once the user receives the alert message regarding the cylinder booking, a pop-up SMS asking for booking directs to the Dialpad.

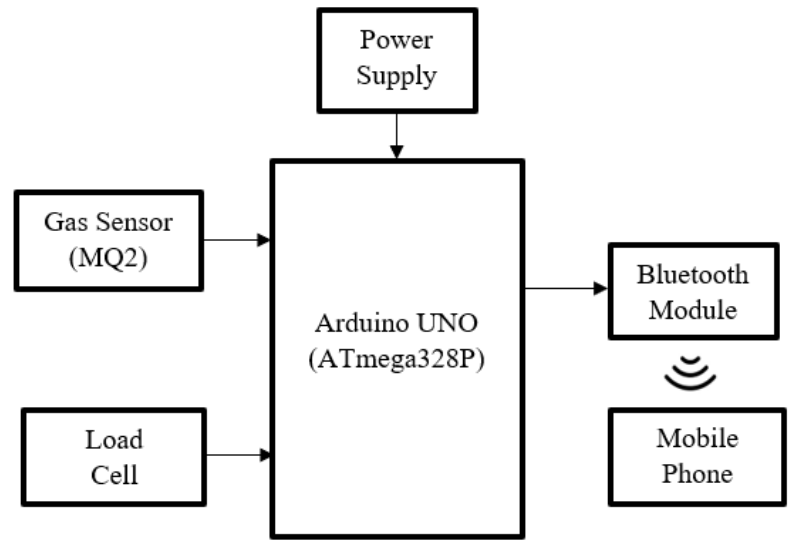

Figure 1 Block Diagram of Existing System 


\subsection{DRAWBACKS OF EXISTING SYSTEM}

- The system only notifies the user if any leakage occurs.

- Bluetooth module is used in this system, so it can be used only within a short range.

- It does not book the new LPG cylinder it only directs the user to the Dialpad.

\section{PROPOSED SYSTEM}

The purpose of this system is,

1. To measure the level of the cylinder by finding the weight.

2. To predict if any gas leakage occurs, notify the user and close the gas valve automatically.

A load cell is used to measure the weight of the cylinder. MQ- 6 sensor is used to detect gas leakage. Node MCU is used to view current level of the cylinder through the mobile application. Thus, gasoline level monitoring, automatic booking and leakage detection can be made in this system.

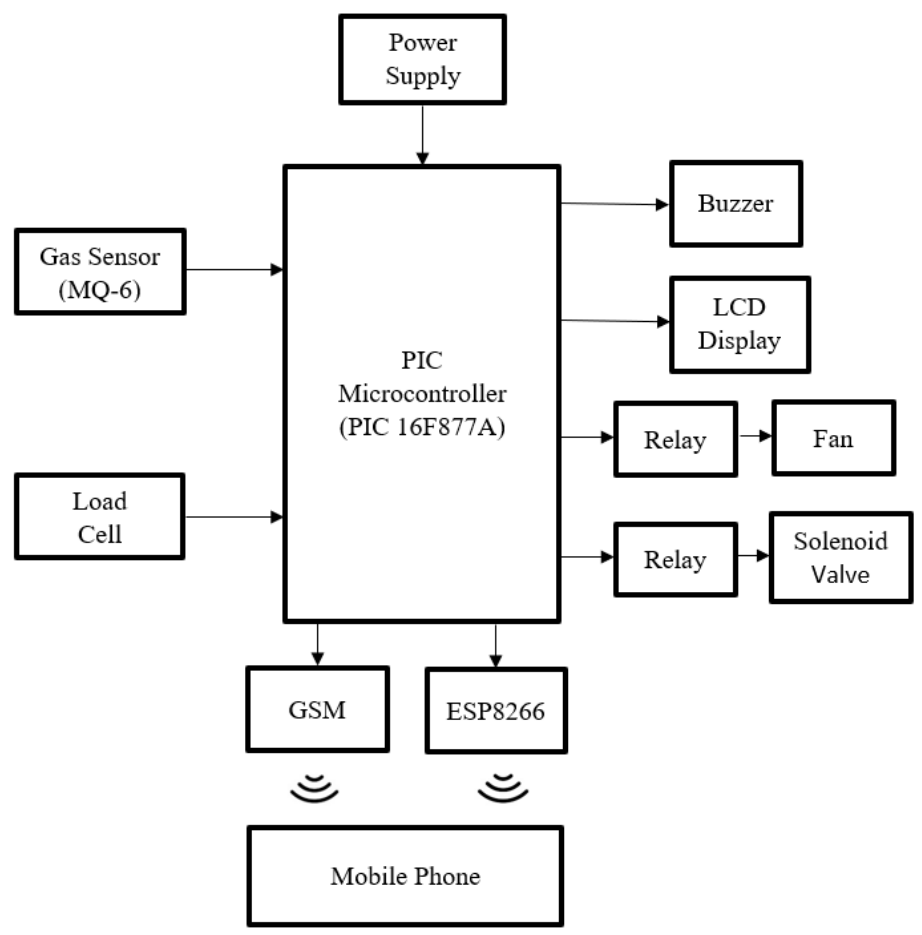

Figure 2 Block Diagram of Proposed System 


\subsection{METHODOLOGY}

A stepdown transformer is used which converts $230 \mathrm{~V}$ to $12 \mathrm{~V} \mathrm{AC}$ supply. This is then converted into 5V DC with the help of the rectifier circuit. Supply is regulated using the voltage regulator. This is given to the PIC microcontroller, load cell, LCD display, Gas sensor (MQ-6), buzzer and exhaust fan. Another supply from the transformer $(24 \mathrm{~V})$ is given to the solenoid valve through the rectifier circuit. A $12 \mathrm{~V}$ supply to the fan is given through the rectifier circuit.

The load cell is used to compute the level of the cylinder by means of weight. The pre-determined values used here are, the load cell is set when the value is set above $3 \mathrm{Kg}$. The weight of the cylinder decreases gradually and once it reaches below $1 \mathrm{Kg}$ a new cylinder is booked automatically. The booking of gas is made with the help of the GSM SIM800c. It sends message to the user and the gas agent regarding new cylinder booking.

MQ-6 sensor is used to detect gas leakage. A gas leakage is detected when the valve of gas leakage goes more than 1 . At the time of gas leakage, the GSM module sends alert message to the user, and also closes the solenoid valve automatically. This also switches $\mathrm{ON}$ the buzzer and the fan. This prevents the system from major accidents which causes damage to life and property. A ESP8266 is used in this system. This helps the user to view gasoline level and leakage level of the cylinder through a mobile application (blynk). This application can be viewed from remote places.

\subsection{HARDWARE DESCRIPTION MICROCONTROLLER}

The microcontroller used in this system is PIC 16F877A. The name PIC refers to Peripheral Interface Controller. It consumes less power and also it is a CMOS 8-bit microcontroller. The Operating speed of PIC in DC is $20 \mathrm{MHz}$ and clock input in DC is 200 ns per instruction cycle. There are 40 pins in it. On examining the device serial ports, parallel ports and five input/output ports are also present. PIC Microcontroller has some factor such as Memory, clock speed, Execution speed and interfacing capability with sensors. PIC has only 35 single word instructions.

\section{GAS SENSOR (MQ-6)}

Presence of gas can be detected using the gas sensors. They are used in safety systems. The sensor is sensitive to gases like LPG, H2, Alcohol. Gas Sensor (MQ-6) is useful for sensing the gas leakage. Measurements can be done very soon due to its high sensitivity. By using the potentiometer, the sensitivity of the gas sensor can be adjusted. The voltage of the sensing element goes high at the time when the LPG gas is detected.

\section{LOAD CELL}

Load cells are used to measure a specific force. In this system we have used $20 \mathrm{Kg}$ load cell. The load cell produces very small output signal and so a separate amplifier is used. We are using Load cell sensor for measuring weight of cylinder. Load cell sensor continuously measure weight of cylinder and send signals to amplifier. 
Most of the load cells uses strain gauge for accurate measurement of the weight. The operating voltage of the load cell is $5 \mathrm{~V}$.

\section{SOLENOID VALVE}

The flow of gases can be controlled using solenoid valve. Solenoid valve can be used efficiently and safely in any systems. Solenoid valve has a plunger for opening and closing operation of the valve, it does not allow the gas to flow through it. It has long cylindrical coil of wire having a large number of turns. A moveable plunger which is also known as an armature is present to control the flow of gas.

\section{RESULTS}

The Figure 3 below shows the hardware image of the proposed system. A cylinder is to be placed on the top of the load cell. This continuously monitors the weight of the cylinder. The gas sensor has high sensitivity and is more sensitive to LPG.

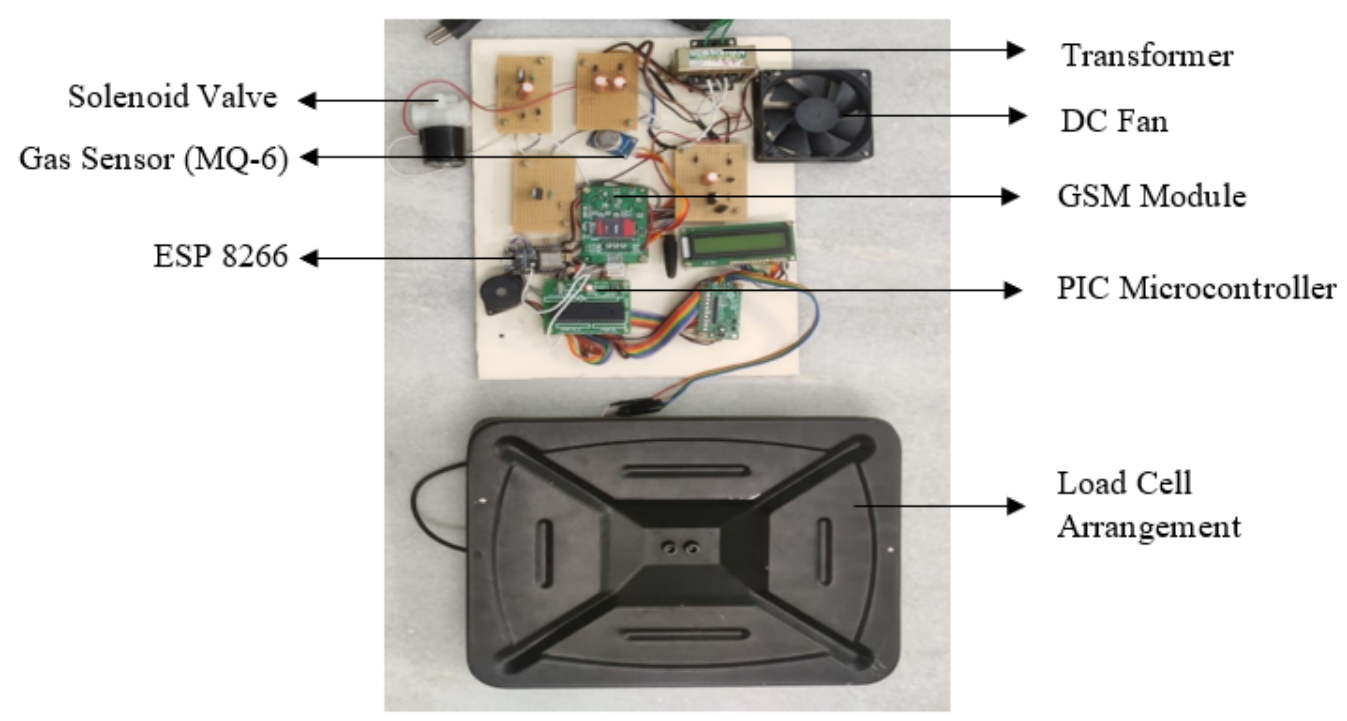

Figure 3 Hardware of Proposed System

A gas Leakage is detected when the leakage value of the gas goes beyond 1. If any gas leakage is detected, it alerts the user through SMS. The weight value is set once the weight of the cylinder is more than $3 \mathrm{Kg}$. The booking information is sent to the user when the weight of the cylinder is critically low i.e., the weight of the cylinder falls below $1 \mathrm{Kg}$. The leakage alert and booking message of the user is shown in the Figure 4 below.

The booking information including the User Name and User ID is sent to the gas agent. With the help of these information the agent can book a new cylinder for the customer. The booking SMS sent to the agent is shown in the Figure 5 below. 


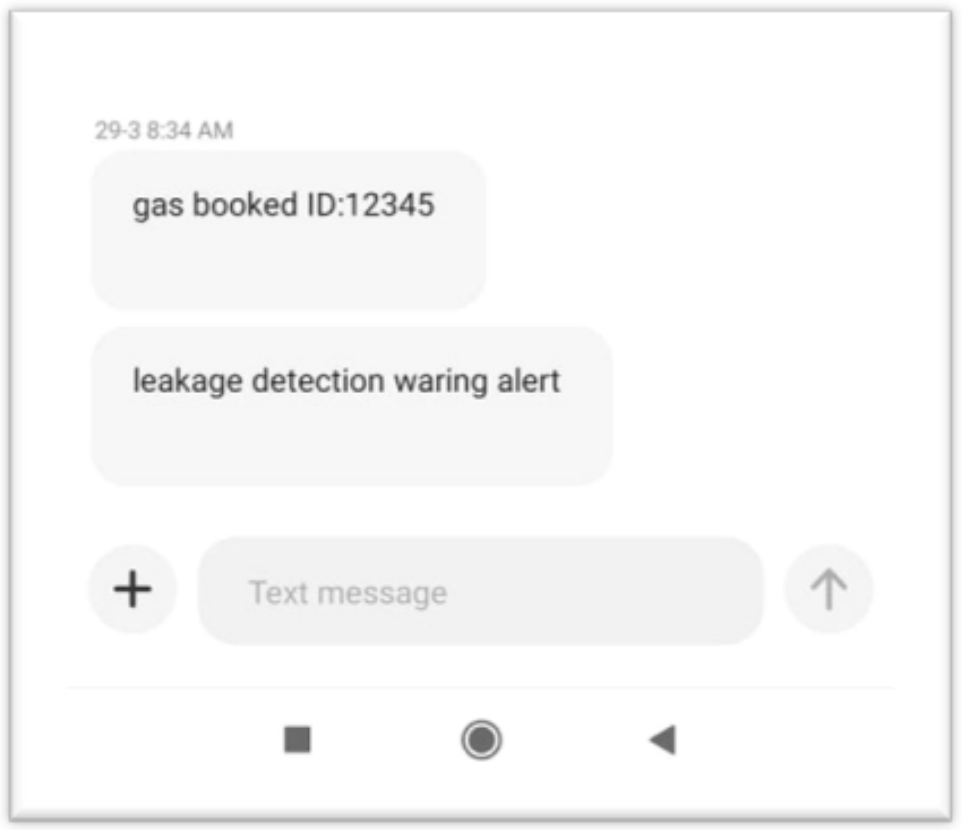

Figure 4 Alert Message to the User

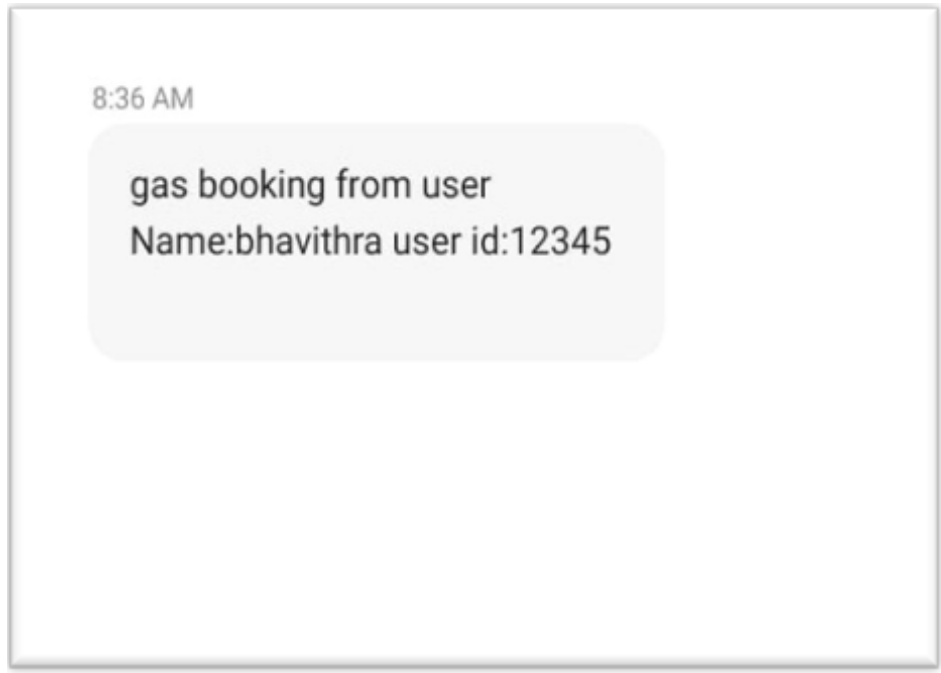

Figure 5 Booking Message to the Gas Agency 
The real time values of level of cylinder and gas leakage level can be viewed with the help of the mobile application. Here, we have used Blynk application for this purpose. The Figure 6 below shows the Blynk application. W is the weight of the cylinder and $l$ is the leakage level.

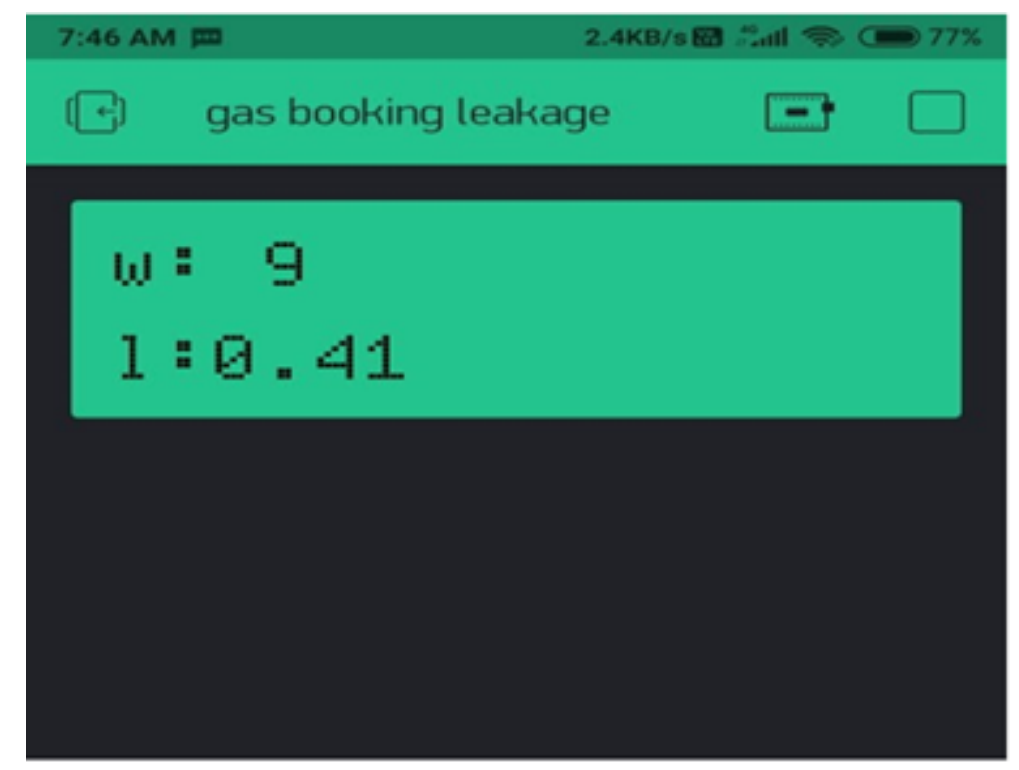

Figure 6 Monitoring Through MobileApplication

\section{CONCLUSION}

The hardware for automatic booking and leakage detection has been developed. The damages caused by the leakage of gas is very dangerous. So, to eradicate this problem, we are introducing highly advanced system. The system mainly focuses on continuous monitoring, booking and leakage detection in LPG cylinder. It helps us to make automatic booking of new gas cylinder if the LPG level goes below the predetermined value. The buzzer is turned on and alert is sent to the user when any gas leakage is detected. The flow of LPG gas to the stove is stopped with the help of the solenoid valve and the fan is switched on to let the leaked gas outside. It helps us in making work easier and provides safety for life and property.

\section{REFERENCES}

Anandhakrishnan, S., Nair, D., Rakesh, K., Sampath, K., Gayathri, S., \& Nair. (2017). IOT Based Smart Gas Monitoring System. IOSR Journal of Electrical and Electronics Engineering, 82-87.

Gupta, J., Rajgire, A. P. S., \& Kadus, T. (Eds.). (2020). Smart LPG and Automatic Booking System using IOT. International Journal of Engineering Research and Technology, 9. 
Keshamoni, K., \& Hemanth, S. (2017). Smart Gas Level Monitoring, Booking and Leakage Detector over IoT. IEEE 7th International Advance Computing Conference.

Mr, A. D., Prabhu, Mr, Ashwin, D., \& Pathak. (2017). Gas Leak Detector using Arduino UNO Microcontroller. International Journal for Research in Applied Science \& Engineering Technology (IJRASET), 5.

Mrs, . K., Durgalakshmi, A., Kaarthikeyan, S., Muruganantham, R. K., \& Kumar. (2020). IoT based Gas Level Detection and the Automatic Booking of the Gas. International Research Journal of Engineering and Technology.

NareshNaik, R., Reddy, P., Kishore, S., \& Reddy, K. K. (Eds.). (2017). Arduino Based LPG gas Monitoring \& Automatic Cylinder booking with Alert System. Journal of Electronics and Communication Engineering (IOSR-JECE), 11.

Pandey, L. K. S. R. C., \& Verma, M. (2017). Internet of things (IOT) based gas leakage monitoring and alerting system with MQ-2 sensor. International Journal of Engineering Development and Research, 5.

Sahu, A. K., Bhaskar, P., Sharma, R. K., Haque, S. S. I. U., Kumar, R., \& Shrivastava. (2017). Gas monitoring using GSM". International Journal for Research in Applied Science \& Engineering Technology (IJRASET), 5, 2321-9653.

Tamizharasan, R. V. T., Sowndariya, M., Sandeep, R., \& Saravanavel. (2019). Retrieved from http://cloudstechnologies.in/cloudtech-admin/downloadtitle/1593138571gas\% 20level\%20detection\%20and\%20automatic\%20booking\%20using\%20iot.pdf

Verma, A., S, P., \& Jayavel, K. (Eds.). (n.d.). Gas Leakage Detection and Smart Alerting and Prediction using IOT. Retrieved from https://ieeexplore.ieee.org/document/7972304 